\title{
Análisis proteómico de Plasmodium, el agente causal de la malaria
}

\author{
Ivone Castro R, Dra en C,(I) María del Carmen Rodríguez G, Dra en C.(I)
}

\section{Castro I, Rodríguez MC. Análisis proteómico de Plasmodium, el agente causal de la malaria. Salud Publica Mex 2009;5 I supl 3:S395-S402.}

\begin{abstract}
Resumen
Los plasmodios son protozoarios cuyo complejo ciclo de vida se lleva a cabo en dos hospederos, el vertebrado y el mosquito. La infección de los seres humanos produce la enfermedad conocida como malaria. La secuenciación del genoma de Plasmodium falciparum y el desarrollo de la proteómica han permitido un gran avance en el conocimiento de la biología de este letal parásito. La presente revisión se centra en describir los logros recientes en el estudio del proteoma de Plasmodium falciparum y algunas de las implicaciones en la búsqueda de nuevos fármacos antimaláricos, así como en la generación de vacunas para el control de la enfermedad.
\end{abstract}

Palabras clave: proteoma; Plasmodium; malaria; México

\section{Castro I, Rodríguez MC.}

Proteomic analysis of Plasmodium,

the causal agent of Malaria.

Salud Publica Mex 2009;5 I suppl 3:S395-S402.

\section{Abstract}

Plasmodia are protozoa whose complex life cycle takes place in two different hosts, the vertebrate and the mosquito. The human infection produces the malaria disease. The genome sequence of Plasmodium falciparum and the proteomic tools have enabled a huge advance in knowledge of the biology of this parasite. This review will focus on the recent advances in proteomic studies of Plasmodium falciparum and some implications for the search of new antimalarial drugs as well as vaccines for the control of the disease.

Key words: proteome; Plasmodium; malaria; Mexico
L os plasmodios, parásitos causantes de la malaria, se transmiten por la picadura de mosquitos Anopheles. Existen más de 100 especies de Plasmodium que infectan reptiles, aves y mamiferos. ${ }^{1,2}$ Plasmodium falciparum es la principal especie causante de malaria en el África tropical y de más de un tercio de las infecciones que se producen en el resto del mundo. ${ }^{3}$

La malaria afecta a 21 países de América Latina, Argentina, Belice, Bolivia, Brasil, Guyana Francesa, Haití, Honduras, México, Nicaragua, Panamá, Paraguay, entre otros, (Organización Panamericana de la Salud, OPS). Del total de 835 millones de habitantes de esta región, 293 millones viven en áreas con riesgo de transmisión de la enfermedad y 203 millones viven en zonas donde ésta es frecuente. ${ }^{3}$ En México, hasta la mitad del siglo pasado, con un promedio anual de 24000 y 2.4 millones de casos, la malaria se hallaba entre las cinco primeras causas de muerte.

El control de la malaria tiene como principio interrumpir la transmisión mediante el abatimiento de

(I) Centro de Investigación Sobre Enfermedades Infecciosas, Instituto Nacional de Salud Pública. Cuernavaca, Morelos, México.

Fecha de recibido: 28 de julio de 2008 • Fecha de aceptado: 9 de diciembre de 2008 Solicitud de sobretiros: María del Carmen Rodríguez. Instituto Nacional de Salud Pública. Av. Universidad 655, col. Santa María Ahuacatitlán. 62100, Cuernavaca, Morelos, México.

Correo electrónico:mrodri@correo.insp.mx 
las poblaciones de mosquitos vectores por medio de insecticidas, eliminar los parásitos a través del tratamiento de los individuos infectados y disminuir el contacto entre humanos y vectores con el recurso de mosquiteros o bien de mejoras en las condiciones de la vivienda. Para mala fortuna, estas estrategias de control conllevan marcadas limitaciones debido a la extensión de las áreas endémicas, la resistencia de los vectores a los insecticidas y de los parásitos a los antimaláricos. A pesar de los esfuerzos de producir vacunas contra la infección en humanos, ninguno de los antígenos probados ha mostrado efectividad. ${ }^{4}$

\section{Ciclo de vida de Plasmodium}

Los plasmodios pertenecen al filum Apicomplexa, ${ }^{5}$ que incluye parásitos que presentan formas invasivas denominadas "zoítos", que a su vez transcurren por tres fases invasivas: merozoítos, oocinetos y esporozoítos (figura 1). En su extremo apical cuentan con organelos (roptrias, micronemas y gránulos densos) ${ }^{6}$ de secreción esenciales en los procesos de motilidad, invasión, biogénesis de la membrana parasitófora y remodelamiento de la célula hospedera. Dada su participación en procesos esenciales del parásito, las proteínas de estos organelos se consideran como moléculas blanco principales para la producción de vacunas antimaláricas. Como otros apicomplexa, Plasmodium tiene proteosoma ${ }^{7}$ y apicoplasto. ${ }^{8}$ El proteosoma consiste en proteasas multiméricas autocompartimentalizadas cuya actividad principal es el control de calidad de las proteínas, la traducción de señales y la regulación del ciclo celular. El apicoplasto es un organelo plastídico no fotosintético que participa en la síntesis de ácidos grasos, isoprenoides y el grupo hemo. ${ }^{9}$

El ciclo de vida de Plasmodium incluye dos hospederos, el vertebrado y el mosquito (figura 2). Durante su desarrollo, Plasmodium expresa proteínas específicas para sobrevivir y desarrollarse en dos ambientes distintos, el intracelular y el extracelular, invadir varios tipos celulares y evadir la respuesta inmunitaria de ambos hospederos.

Cuando el mosquito se alimenta con la sangre del hospedero vertebrado, inyecta esporozoítos, los cuales alcanzan el hígado, invaden los hepatocitos y se convierten en esquizontes y después en merozoítos, la siguiente fase invasiva, dotada de organelos secretores que les permiten invadir eritrocitos. Dentro del eritrocito, los parásitos se encuentran en una vacuola parasitófora donde pueden seguir dos vías de desarrollo: crecer y diferenciarse en esquizontes productores de nuevos merozoítos, que invaden a otros eritrocitos, o producir formas sexuales: gametocitos macho y hembra. Cuando

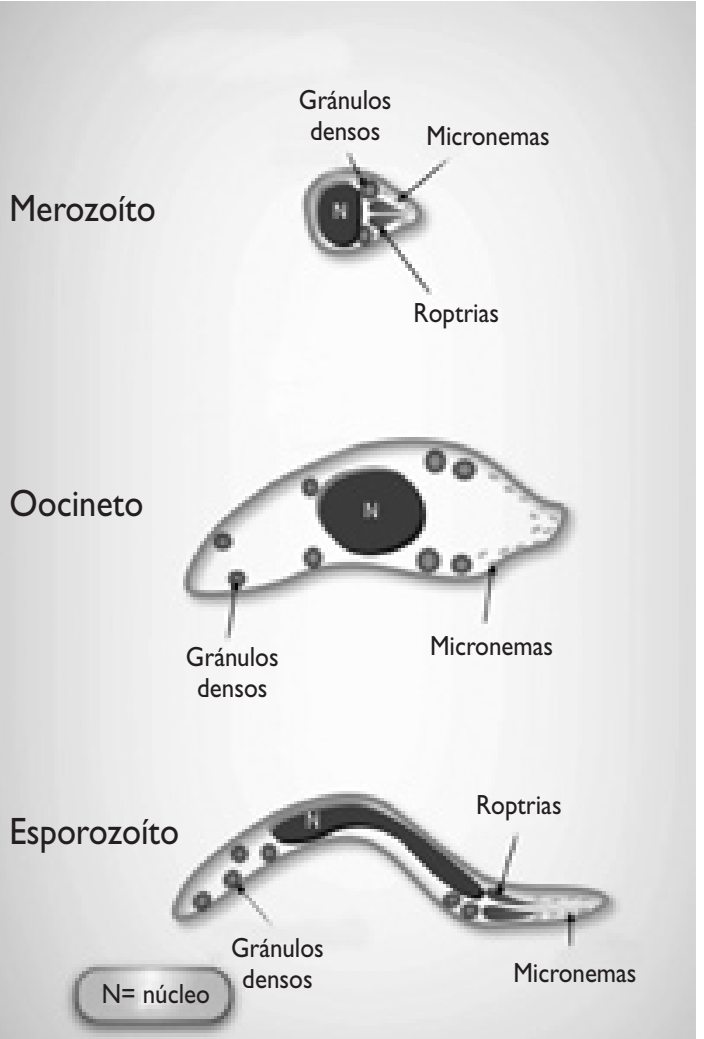

Figura I. Esquema de las fases invasivas de Plasmodium EN EL QUE SE MUESTRAN LOS ORGANELOS APICALES (ROPTRIAS, MICRONEMAS Y GRÁNULOS DENSOS), QUE CONSTITUYEN EL COMPLEJO APICAL REPRESENTATIVO DE LOS "Zoítos" DE PARÁSITOS DEL FILUM APICOMPLEXA

un mosquito susceptible toma los gametocitos, tiene lugar otra etapa del ciclo evolutivo del parásito durante la cual se diferencian en gametos macho y hembra, que al fecundarse originan cigotos; estos últimos acaban por transformarse en oocinetos móviles. Los oocinetos invaden el epitelio intestinal del mosquito hasta alcanzar la lámina basal, donde se convierten en ooquistes y producen miles de esporozoítos. Los esporozoítos se liberan a la hemolinfa, por medio de la cual se distribuyen en todo el cuerpo del mosquito e invaden las glándulas salivales; es desde estas glándulas que son inoculados en el hospedero cuando el mosquito se alimenta y de esa manera se reinicia el ciclo (figura 2).

\section{Proteómica de Plasmodium}

Uno de los mayores logros científicos en la investigación moderna del parásito de la malaria fue la secuenciación 


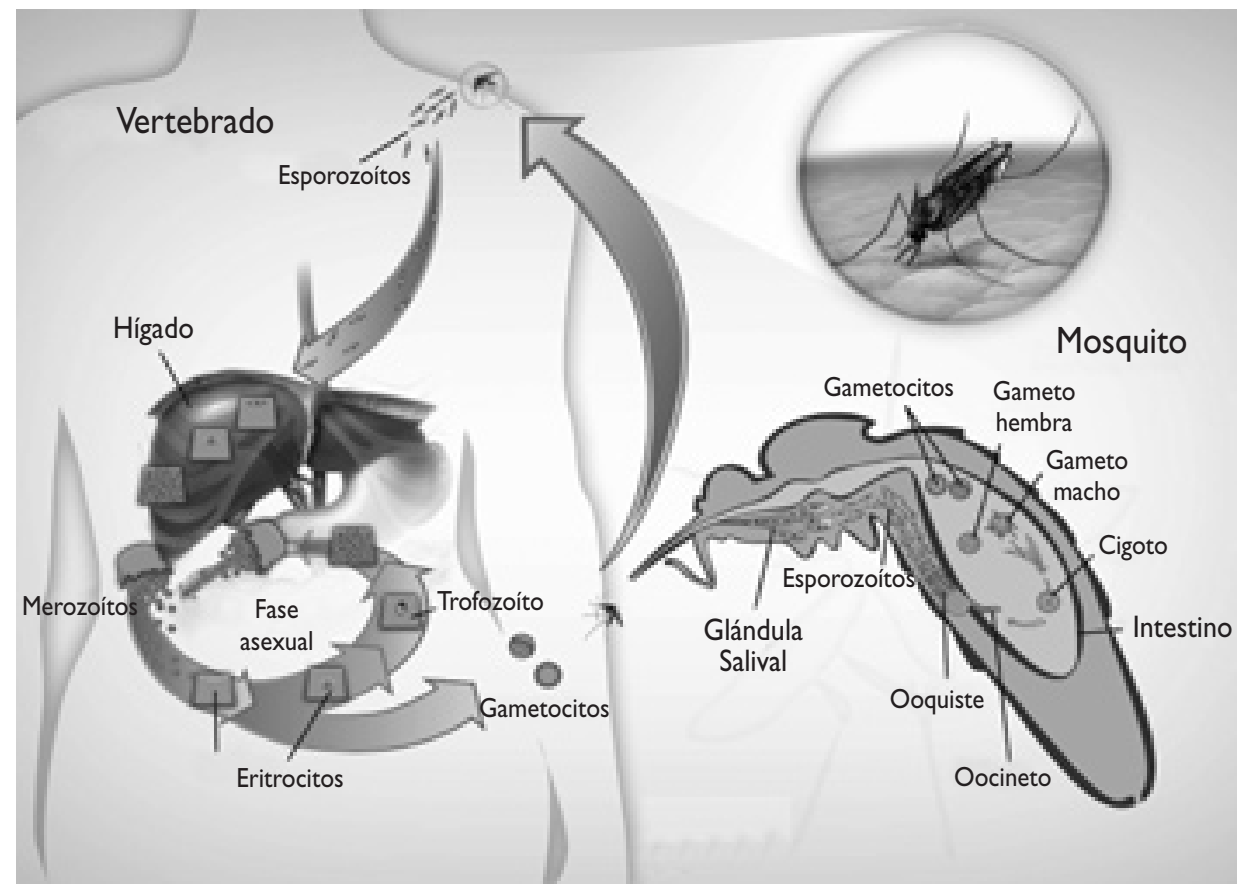

Figura 2. Ciclo de vida de Plasmodium sp. El parásito se desarrolla tanto en el hospedero vertebrado como en el MOSQUITO. LA FASE ASEXUAL SE LLEVA A CABO EN EL HÍGADO Y EN LOS ERITROCITOS, CON LA CONSECUENTE PRODUCCIÓN DE LOS GAMETOCITOS; ÉSTOS SON TOMADOS POR EL MOSQUITO ANOPHELES, EN CUYO INTERIOR SE DESARROLLAN EN ESPOROZOÍTOS. LOS ESPOROZOÍTOS SON TRANSPORTADOS HACIA LAS GLÁNDULAS SALIVALES DEL MOSQUITO, DE DONDE SON INOCULADOS AL HOSPEDERO VERTEBRADO, PARA DAR INICIO A UN NUEVO CICLO

del genoma de Plasmodium falciparum, ${ }^{10,11}$ que al practicarse a gran escala proporcionó una gran cantidad de secuencias de ADN, no obstante las cuales aún se desconoce la función biológica de la mayoría de las proteínas que codifican los genes identificados, por lo que el estudio funcional es forzoso en esta era posgenómica.

La proteómica (el análisis a gran escala de los productos de un genoma mediante métodos bioquímicos) permite obtener una visión global e integrada de los procesos celulares. Esta herramienta ha contribuido en forma relevante al establecimiento de la conexión entre las secuencias genómicas y su función biológica.

La falta de métodos de separación y análisis rápidos y sensibles había limitado la efectividad en la identificación. En el decenio de los años noventa, la espectrometría de masas ${ }^{12}$ surgió como un método analítico muy poderoso, y eliminó la mayor parte de las limitaciones para ello. Sin embargo, no fue sino hasta la presente década que la combinación de la espectrometría de masas con la electroforesis bidimensional y el análisis bioinformático hicieron posible la identificación de proteínas a gran escala.
Tres factores han resultado decisivos para el desarrollo de la proteómica: a) la secuenciación de genomas a gran escala y el desarrollo de bases de datos de secuencias de proteínas; $b$ ) el perfeccionamiento de las técnicas que permite una mejor resolución de los pesos moleculares (PM) para análisis y discriminación de secuencias peptídicas; c) los avances realizados en la separación de proteínas mediante electroforesis bidimensional con la introducción de los gradientes de $\mathrm{pH}$ inmovilizados. ${ }^{13}$

El estudio de proteomas de parásitos intracelulares como Plasmodium requiere suficientes cantidades de material parasitario, con mínima contaminación de material del hospedero, lo que ha limitado el análisis proteómico de fases específicas de desarrollo, como las hepáticas, sexuales o fracciones subcelulares. Sin embargo, el uso de perlas magnéticas cubiertas con anticuerpos monoclonales permitió purificar esporozoítos ${ }^{14} \mathrm{y}$ el empleo de líneas transgénicas de Plasmodium que expresan la proteína verde fluorescente (GFP) bajo el control de promotores específicos de sexo permitió la purificación de gametocitos machos y hembras por medio de citometría de flujo. ${ }^{15}$ 
Las dificultades para su purificación han obstaculizado el estudio de componentes proteínicos subcelulares de roptrias, micronemas y gránulos densos de Plasmodium; sólo los componentes proteínicos de las roptrias de los merozoítos, proteínas que participan en la biogénesis de la membrana parasitófora, han sido identificados a través de estudios proteómicos y de la bioinformática. ${ }^{16}$

\section{Proteómica de las fases asexuales de Plasmodium}

La vacuola parasitófora representa la interfaz entre el parásito y el ambiente de la célula hospedera. El análisis proteómico del eritrocito humano ${ }^{17}$ identificó 181 proteínas específicas, de las cuales la mitad reside en la membrana plasmática y el resto en el citoplasma. Este estudio proporcionó las bases para entender los cambios metabólicos y estructurales inducidos por una infección malárica y contribuyó a entender las complejas relaciones que se presentan entre el hospedero y el parásito.

La proteómica ha permitido conocer los componentes moleculares y los cambios en la expresión de las proteínas durante las diferentes fases del desarrollo de Plasmodium. ${ }^{18}$ El análisis del contenido proteínico de la cepa NF-54 de P. falciparum concluyó que hay 1289 proteínas específicas correspondientes a $23 \%$ de la predicción del proteoma. ${ }^{10,11}$ De éstas, 714 correspondieron a las fases asexuales (trofozoítos y esquizontes), 931 a gametocitos y 645 a gametos. Estos resultados coincidieron con los de otros estudios ${ }^{14}$ en la identificación de proteínas específicas de estas fases, entre ellas AMA-1 (antígeno 1 de la membrana apical de merozoítos), una proteína del merozoíto que interviene en el proceso de invasión del eritrocito; CLAG-9 (proteína asexual de adherencia celular), relacionada con la adherencia celular; MESA (antígeno de superficie del eritrocito infectado con merozoítos); MSP-1 (proteína 1 de la superficie del merozoíto), otra proteína del merozoíto que posibilita la invasión del eritrocito. También se identificaron proteínas específicas de fases sexuales como Actina II, Pf-16 (antígeno específico de gametocitos), Pfs-48/45 (específicas de gametos en relación con el proceso de fertilización), ${ }^{19}$ Pf-230 (específica de gametos). ${ }^{20}$ Como hecho interesante, también se caracterizó un grupo de proteínas con dominios que indican su posible participación en interacciones intercelulares y que son blancos potenciales para la producción de vacunas.

Otro estudio demostró que $P$. falciparum presenta un alto nivel de regulación de la expresión de sus genes en sus cuatro estadios de desarrollo. ${ }^{14}$ Este estudio identificó 2415 proteínas, de las cuales 51\% de las que se expresan es hipotético.
En general, los análisis proteómicos de los diferentes estadios parasitarios ${ }^{14}$ identificaron 439 proteínas predichas (18\% del total de proteínas identificadas), que contienen al menos un dominio transmembranal o un tallo de glucosil-fosfatil-inositol (GPI) para anclar a la membrana plasmática. También se identificaron 304 proteínas solubles con una señal para ser enviadas a la vía secretora o hacia algún organelo. Lo interesante de este grupo es que no presentó homología con otras proteínas del hospedero, lo cual las convierte en blancos potenciales para el desarrollo de vacunas o de nuevos antimaláricos. También se identificaron varias proteínas exclusivas de cada fase y sólo $6 \%$ que se observan en todas las fases de desarrollo. El perfil funcional de las proteínas identificadas en el esporozoíto indicó que casi todas se asocian con organelos apicales, mientras que en merozoítos, trofozoítos y gametocitos éstas guardan una relación más importante con la síntesis y el destino de las proteínas (ensamblaje, modificaciones, etc.) y con el metabolismo, mientras que en los gametocitos y trofozoítos, el mayor número de proteínas se relacionó con la transcripción y el transporte celular.

El estudio de Florens y colaboradores ${ }^{14}$ reveló que la expresión de los genes var y rif (dos familias de genes que codifican para moléculas de superficie de eritrocitos infectados con Plasmodium y que permiten que éstos se adhieran al endotelio vascular y participen en la evasión a la respuesta inmunitaria del hospedero vertebrado), antes considerada específica de la fase eritrocítica, también se expresa en gran y variada cantidad en los esporozoítos, lo que indicaría que estas proteínas tal vez participan en los procesos generales de interacción con las células del hospedero vertebrado y/o en la evasión inmunitaria. Lo anterior no deja de llamar la atención en cuanto a que la regulación específica de estadio de Plasmodium no es tan exacta como se suponía.

Un mecanismo de control de la expresión de proteínas que contribuye a la especificidad de estadio en $P$. falciparum se deriva del agrupamiento (cluster) de genes codificantes en los cromosomas. Los agrupamientos de genes descritos en este estudio demuestran un amplio y variado orden de organización cromosómica, el cual probablemente corresponde a regiones abiertas de la cromatina que permiten la expresión de los genes corregulados. ${ }^{14}$

\section{Proteómica de organelos subcelulares de Plasmodium}

Las proteínas de las roptrias del merozoíto participan en la biogénesis de la vacuola parasitófora (PV).6,21 Antes, lo único que se conocía era un número limitado de proteínas específicas de estos organelos. En la 
actualidad, mediante modelos experimentales con $P$. berghei, P. yoelii y P. chabaudi que infectan a roedores y las herramientas de la proteómica junto con la Tecnología Multidimensional de Identificación de Proteínas (MudPIT), ${ }^{22}$ tecnología que no incluye la utilización de geles electroforéticos, se han identificado más proteínas específicas de estos organelos.

Un estudio identificó 40 proteínas específicas de una fracción enriquecida de roptrias aisladas de los merozoítos de las tres especies de Plasmodium de roedores. ${ }^{16}$ Este estudio incluyó un análisis diferencial de las proteínas de las fracciones apicales aisladas comparadas con proteínas totales extraídas de otros organelos vesiculares de las fases asexuales y sexuales, pero encontró una significativa contaminación con componentes citoplásmicos (proteínas de choque térmico, proteínas ribosómicas, factores de elongación, etc), y con 27 unidades del proteosoma, de las cuales 13 se encontraron enriquecidas en las fracciones de roptrias. También se encontró una alta contaminación con enzimas metabólicas citoplasmáticas, tres de ellas involucradas en la biosíntesis de coenzimas o el metabolismo de lípidos. Una de las enzimas, la biosintetasa de piridoxal, interviene en una vía alternativa de la forma 5-piridoxal fosfato, que es una coenzima esencial de numerosas enzimas con funciones diversas. Los humanos no sintetizan dicha coenzima, por lo que se considera un blanco potencial para el desarrollo de antimaláricos. Debido a que los parásitos de la malaria no sintetizan purinas de novo, la enzima transferasa de hipoxantina-guanina-xantina-fosforibosilo (HGXPRT), encargada de catalizar la fosforilación de la hipoxantina, la guanina y la xantina, se considera un blanco para el desarrollo de medicamentos.

\section{Proteómica de las fases sexuales de Plasmodium}

El desarrollo sexual de Plasmodium juega un papel central en la transmisión de la malaria. Los gametocitos, precursores de los gametos, se encuentran en la circulación del hospedero vertebrado y son los responsables de la transmisión al mosquito vector, lo que ubica a las proteínas de estas fases como blancos atractivos para desarrollar estrategias que prevengan la transmisión de la enfermedad.

La biología de los gametocitos machos y hembras difiere y estas diferencias se evidenciaron en las proteínas identificadas en el análisis de sus proteomas. ${ }^{15}$ Los gametocitos circulantes se encuentran en fase de detención del ciclo celular (G0). En el estómago del mosquito experimentan un proceso de activación que resulta en la salida del eritrocito y la diferenciación a gametos machos y hembras. El gameto macho replica su genoma y genera ocho gametos móviles, los cuales encuentran y fertilizan gametos hembra en menos de $30 \mathrm{~min}$. La fertilización produce un cigoto que se transforma en oocineto y luego en ooquiste. ${ }^{23}$

La expresión de GFP bajo el control de promotores específicos de sexo facilitó el análisis de los proteomas de gametocitos machos y hembras purificados por citometría de flujo y analizados por espectrometría de masas. ${ }^{15}$ La distribución de las proteínas predichas a partir de los dos proteomas mostró una divergencia funcional entre machos y hembras. Estos proteomas compartieron sólo 69 proteínas, con una divergencia de 236 proteínas del macho y 101 proteínas de la hembra. Uno de los hallazgos interesantes de este estudio fue la presencia de 29 proteína cinasas y fosfatasas, varias de ellas específicas de sexo, dos de las cuales participan en la diferenciación celular en gametocitos machos (MAP-2) y en la meiosis posfertilización (NEK-4). La presencia de proteína cinasas específicas por sexo indicó la existencia de refinamientos específicos en las vías de traducción de señales.

En el gameto macho se encontraron proteínas relacionadas con el axonema ${ }^{24}$ y con la replicación del genoma, mientras que en el proteoma del gametocito hembra se encontraron abundantes péptidos ribosómicos y mitocondriales, hallazgo que concuerda con abundantes ribosomas (y reticulo endoplásmico) en el gametocito hembra, así como también con las complejas y abundantes mitocondrias que éste posee. ${ }^{25}$

Como dato de interés, en ambos proteomas se encontraron abundantes proteínas del apicoplasto, lo que resulta muy sugestivo de la posible participación de este organelo en el desarrollo del gametocito macho, no obstante que la herencia del genoma del apicoplasto sólo tiene lugar por línea materna. ${ }^{26}$ El estudio proteómico de los gametocitos también coincidió con la identificación de proteínas específicas del proceso de fertilización (P$48 / 45),{ }^{19}$ la proteína específica de gametocitos hembra (P-27), ${ }^{25}$ y la proteína específica de gametocitos machos (P-230p). ${ }^{19}$ Este estudio proteómico fue el primero en proporcionar una lista de proteínas específicas de los gametocitos y la única lista de proteínas específicas de sexo de Plasmodium. La investigación futura de estas proteínas proveerá nueva información sobre la biología y diferenciación sexual de los gametocitos, junto con las estrategias que utiliza el parásito para sobrevivir en el intestino del mosquito vector, lo cual muy posiblemente resultará en la identificación de posibles blancos para la interrupción de la transmisión, ya sea por medio de fármacos o vacunas. 


\section{La proteómica y la búsqueda de antimaláricos}

En los últimos años se registró un incremento importante en la resistencia de los parásitos a la acción de compuestos antimaláricos. Diversos grupos se han enfocado al estudio de los mecanismos que intervienen en esta resistencia, así como a la búsqueda de nuevos blancos potenciales para desarrollar nuevos productos medicinales. Una de las teorías más aceptadas para la acción de las quinolonas en el tratamiento de la malaria es su interferencia con la detoxificación del grupo hemo dentro del eritrocito. ${ }^{27}$ Mediante una herramienta de la proteómica conocida como "Proteome Mining", Graves $\mathrm{y} \mathrm{col} .{ }^{28}$ identificaron dos proteínas con actividad enzimática conocidas como QR-2 (reductasa de quinona) y ALDH-1 (deshidrogenasa de aldehído). Estas dos enzimas son blancos selectivos de unión a quinolonas (cloroquina, primaquina, mefloquina) e inhiben su función. Las dos proteínas se expresan en células humanas y no en P. falciparum. La función principal de la QR-2 es catalizar la detoxificación metabólica de las quinonas, las cuales se encuentran en todas las plantas y células animales, por lo que se cuenta con la hipótesis de que la inhibición de QR-2 en los eritrocitos daría como resultado la generación de estrés oxidativo en la célula y con ello un ambiente inviable para Plasmodium.

Con el recurso de la electroforesis y la espectrometría de masas, Makanga y col. ${ }^{26}$ evaluaron el efecto de un nuevo antimalárico (Coartem), cuyos componentes activos son Artemeter (ARM) y Lumefantrina (LUM). Este fármaco ha mostrado ser uno de los agentes terapéuticos más prometedores para combatir la multirresistencia de P. falciparum..$^{29}$ No se conoce en su totalidad el mecanismo de acción de cada uno de los componentes de Coartem. El análisis del proteoma del parásito mostró un patrón de expresión de proteínas de acuerdo al tratamiento, con ARM o LUM, lo que demuestra de manera adicional la especificidad de cada tratamiento. Asimismo, se observó que ARM muestra un efecto reductor de la expresión de algunas enzimas glucolíticas (enolasa, cinasa de fosfoglicerato, aldolasa de fructosa difosfato, deshidrogenasa de gliceraldehído-3-fosfato), en tanto que LUM inhibe su expresión y tiene la propiedad de regular el metabolismo de Plasmodium. Estos estudios mostraron que la proteómica es una herramienta útil para evaluar compuestos con propiedades antimaláricas que en un futuro podrían sustituir a las que se han vuelto obsoletas debido a la resistencia de Plasmodium.

\section{La proteómica y el desarrollo de vacunas contra la malaria}

El desarrollo de una vacuna contra la malaria es un reto importante en un mundo en el cual millones de personas se infectan cada año y otras más mueren a consecuencia de esta enfermedad. ${ }^{30}$ Empero, el desarrollo de una vacuna contra la malaria ha sido difícil por la complejidad del ciclo de vida del parásito y la respuesta del hospedero ante la presencia de éste.

Entre los problemas para el desarrollo de vacunas efectivas se incluyen la existencia de más de 5300 proteínas a partir del genoma $(23 \mathrm{Mb})$, la expresión de proteínas específicas por sexo y estadio parasitario y el requerimiento de mecanismos de respuesta inmunológica para blancos específicos de cada estadio, ${ }^{31}$ de forma que identificar proteínas que intervienen en la interacción hospedero-parásito es de suma importancia para la selección de antígenos útiles que induzcan respuestas inmunitarias eficientes que eliminen la infección.

Existen dos estrategias principales para el desarrollo de vacunas antimaláricas. Una propone maximizar la magnitud y la calidad de la respuesta inmunitaria contra uno o varios antígenos, tales como la proteína circunesporozoítica de los esporozoítos (CSP) o la MSP-1 de los merozoítos, ambas por medio de la inmunización con péptidos sintéticos o proteínas recombinantes con adyuvantes. ${ }^{32}$ La inmunización con vacunas formuladas con la CSP y un fuerte adyuvante proporcionó protección a corto plazo a voluntarios retados de manera experimental e individuos semiinmunes contra infecciones transmitidas de forma natural. La segunda estrategia consiste en combinar antígenos blanco para inducir una buena respuesta inmunitaria contra ellos, por ejemplo, primero inmunizando con $\mathrm{ADN}$ plasmídico y después reforzando con $\mathrm{ADN}$, virus o proteínas recombinantes. Otro tipo de vacunas que bloquean la transmisión están dirigidas a inducir anticuerpos contra los estadios sexuales de Plasmodium.

Un requerimiento para la inducción de diferentes tipos de respuesta inmunitaria por medio de la vacunación depende del estadio de vida de Plasmodium en el cual se exprese la proteína, por lo que la identificación de antígenos putativos específicos de estadio resulta de gran importancia. En este sentido, los análisis MudPIT de diferentes preparaciones de parásitos han aportado un listado muy grande de proteínas que se expresan de manera diferencial en las distintas fases del ciclo de vida del parásito, lo que servirá de base para identificar blancos potenciales. En fecha reciente se demostró que 
16 de 27 proteínas putativas de $P$. falciparum identificadas por MudPIT fueron reconocidas por voluntarios inmunizados con esporozoítos irradiados; nueve proteínas fueron muy antigénicas, tres presentaron reactividad intermedia y cuatro fueron algo antigénicas. ${ }^{31}$

\section{Perspectivas y conclusiones}

Los plasmodios son microorganismos complejos que han coevolucionado con sus hospederos mosquitos y vertebrados por millones de años. Diseñar antimaláricos y vacunas que interrumpan su ciclo de vida de manera sustancial y persistente es un reto que requiere entender su biología. Los avances recientes en la genómica y la proteómica ofrecen grandes oportunidades para vencer este reto en un futuro no muy lejano. ${ }^{14}$

La reciente secuenciación del genoma humano, de An. gambiae, P. falciparum y $P$. vivax es relevante para el estudio de la malaria humana ya que permite la aplicación de tecnologías modernas de proteómica para complementar las estrategias de control convencionales. El análisis proteómico ha permitido dilucidar los perfiles de expresión global de las proteínas, la localización subcelular de los productos génicos y las interacciones entre el hospedero y el agente patógeno que son centrales para la patogénesis y el tratamiento de la enfermedad.

En conjunto, la proteómica ha aportado un material valioso para futuras investigaciones con proteínas que proporcionan alternativas en el desarrollo de medicamentos o vacunas capaces de bloquear el desarrollo del parásito, con lo cual se evitaría su desarrollo en el hospedero vertebrado y/o su transmisión al mosquito y como consecuencia a otros seres humanos. Sin embargo, el requisito más importante para definir su potencial es conocer la función específica de las proteínas identificadas.

\section{Agradecimientos}

Las autoras agradecen a Mario H. Rodríguez y Jesús Martínez-Barnetche sus comentarios y sugerencias para la elaboración de este artículo; a Juan Carlos Rodríguez y Nancy Nava por su ayuda y entusiasmo en el diseño de las figuras.

\section{Referencias}

I. Garham PCC. Malaria parasites and other Haemosporidia. Blackwell Scientific: Oxford, 1966.

2. Garham PCC. Malaria parasites in man: life cycles and morphology (excluding infrastructure). En:Wernsdorfer WH, McGregor I (eds): Malaria. Vol. I Churchill-Livingstone: Edinburgh, 1988:6I-96.
3. Organización Mundial de la Salud 2002.WHO Report. Disponible en: http://www.who.int/infectious-disease-report/2002/index.htlm. 4. Mendis K, Sina BJ, Marchesini P, Carter R. The neglected burden of Plasmodium vivax malaria. Am J Trop Med Hyg 2001;64:97-106. 5. Levine ND. En: Hammond DM, Long PL (eds.):The Coccidia Eimeria, Isospora,Toxoplasma and related Genera. University Park Press: Baltimore, USA 1973:I-22.

6. Dubremetz JF, Garcia-Reguet N, Conseil V, Fourmaux MN.Apical organelles and host-cell invasion by apicomplexa. Int J Parasitol 1998;28:1007-1013.

7. Gille C, Goede A, Schloetelburg C, Preissner R, Kloetzel PM, Gobel UB, et al.A comprehensive view on proteasomal sequences: implications for the evolution of the proteasome.J Mol Biol 2003;326: I 437-I448. 8. Fichera ME, Roos DS.A plastid organelle as a drug target in apicomplexan parasites. Nature 1997;390:407-409.

9. Foth BJ, McFadden GI.The apicoplast: a plastid in Plasmodium falciparum and other apicomplexan parasites. Int Rev Cytol 2003;224:57-I I0.

I0.Gardner MJ, Shallom S], Carlton JM, Salzberg SL, NeneV, Shoaibi A, et al. Sequence of Plasmodium falciparum chromosome 2, 10, II and I4. Nature 2002a;419:53।-534.

I I. Gardner MJ, Hall N, Fung E, White O, Berriman M, Hyman RW, et al. Genoma sequence of the human malaria parasite Plasmodium falciparum. Nature 2002b;419:498-5II.

I2. Fenn JB, Mann M, Meng CK, Wong SF, Whitehouse CM. Electrospray ionization for mass spectrometry of large biomolecules. Science |989;246:64-7|

13. O'Farrell PH. High resolution two-dimensional electrophoresis of proteins.J Biol Chem 1975;250:4007-4021.

I4. Florens L,Washburn MP, Raine JD, Anthony RM, Graiger M, Haynes JD, et al. A proteomic view of the Plasmodium falciparum life cycle. Nature 2002;419:520-526.

I5. Khan SM, Franke-Fayard B, Mair GR, Lasonder E, janse C], Mann M, et al. Proteome analysis of separated male and female gametocytes reveals novel sex-specific Plasmodium biology. Cell 2005; I 2 :675-687.

16. Sam-Yellow TY, Florens L,Wang T, Raine JD, Carucci DJ, Sinden R, et al. Proteome analysis of rhoptry-enriched fractions isolated from Plasmodium merozoites.J Proteomic Res 2004;3:995- I00I.

17. Kakhniashvili DG, Bulla LA, Jr., Goodman SR. The human erythrocyte proteome: analysis by ion trap mass spectrometry. Mol Cell Proteomics 2004;3:50I-509.

18. Lasonder E, Ishihama Y, Andersen JS, Vermunt AM, Pain A, Sauerwein RW, et al. Analysis of the Plasmodium falciparum proteome by highaccuracy mass spectrometry. Nature 2002;419:537-542.

19.Van Dijk MR, Janse CJ,Thompson J,Waters AP, Braks JA, Dodemont $\mathrm{HJ}$, et al.A central role for P48/45 in malaria parasite male gamete fertility. Cell 200I; I04(I):153-164.

20.Williamson KC, Criscio MD, Kaslow DC. Cloning and expression of the gene for Plasmodium falciparum transmission-blocking target antigen, Pfs230. Mol Biochem Parasitol 1993;58:355-358.

21. Sam-Yellowe TY. Rhoptry organelles of the apicomplexa:Their role in host cell invasion and intracellular survival. Parasitol Today 1996; |2:308-3 I6. 22.Wolters DA, Washburn MP, Yates JR, 3rd.An automated multidimensional protein identification technology for shotgun proteomics. Anal Chem 2000;73:5683-5690.

23. Vaidya AB, Morrisey J, Plowe CV, Kaslow DC, Wellems TE.

Unidirectional dominance of cytoplasmic inheritance in two genetic crosses of Plasmodium falciparum. Mol Cell Biol 1993;13:7349-7357. 24. Rawlings DJ, Fujioka H, Fried M, Keister DB,Aikawa M, Kaslow DC. Alpha-tubulin II is a male-specific protein in Plasmodium falciparum. Mol Biochem Parasitol 1992;56:239-250.

25. Janse CJ,Waters AP. Sexual development of malaria parasites. En:AP Waters AO, Janse CJ (eds.): Malaria parasites: genomes and molecular biology.Wymondham: United Kingdom, Caister Academic Press:445-474. 
26. Makanga M, Bray PG, Horrocks P,Ward SA. Towards a proteomic definition of CoArtem action in Plasmodium falciparum malaria. Proteomics 2005;5: 1849-1858.

27. Foley M,Tilley L. Quinoline antimalarials: mechanisms of action and resistance and prospects for new agents. Pharmacol Ther 1998;79:55-87. 28. Makanga M, Bray PG, Horrocks P, Ward SA. Towards a proteomic definition of CoArtem action in Plasmodium falciparum malaria. Proteomics 2005;5: 1840-I858.

29. Graves PR, Kwiek JJ, Fadden P, Ray R, Hardeman K, Coley AM, et al. Discovery of novel targets of quinoline drugs in the human purine binding proteome. Mol Pharmacol 2002;62:1364-1372.
30. Meshnick SR.Artemisinin: mechanism of action, resistance and toxicity. Int J Parasitol 2002;32:1655-1660.

31. Biagini GA, O'Neil PM, Nzila A,Ward SA, Bray PG.Antimalarial chemotherapy: young gungs or back to the future? Trends Parasitol 2003; |9:479-487.

32. Doolan DL, Aguiar JC, Weiss WR, Sette A, Felgner PL, et al .Utilization of genomic sequence information to develop malaria vaccines.J Exp Biol 2003;206:3789-3802. 